Cipango $\begin{aligned} & \text { Cipango } \\ & \text { Cahiers d'études japonaises }\end{aligned}$

15 | 2008

Guerre, colonialisme et commémoration

\title{
Ethnographie du rite du Gohō du temple Ryōsanji
}

\section{Coline Selmo}

\section{(2) OpenEdition}

\section{Journals}

Édition électronique

URL : https://journals.openedition.org/cipango/168

DOI : $10.4000 /$ cipango. 168

ISSN : 2260-7706

Éditeur

INALCO

Édition imprimée

Date de publication : 1 janvier 2008

Pagination : 300-301

ISBN : 978-2-85831-177-4

ISSN : $1164-5857$

Référence électronique

Coline Selmo, «Ethnographie du rite du Gohō du temple Ryōsanji », Cipango [En ligne], 15 | 2008, mis en ligne le 14 novembre 2011, consulté le 30 juin 2021. URL : http://journals.openedition.org/cipango/ 168 ; DOI : https://doi.org/10.4000/cipango.168

Ce document a été généré automatiquement le 30 juin 2021.

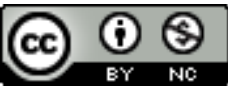

Cipango est mis à disposition selon les termes de la Licence Creative Commons Attribution - Pas d'Utilisation Commerciale 4.0 International. 


\title{
Ethnographie du rite du Gohō du temple Ryōsanji
}

\author{
Coline Selmo
}

\section{RÉFÉRENCE}

Ethnographie du rite du Gohō du temple Ryōsanji, Mémoire de Master 2 soutenu par Coline Selmo (Paris 7-Diderot, 2008), sous la direction d'A. Brotons.

1 Ce mémoire traite du rite du Gohō (Gohōsai 護法祭), un rite de possession issu du shugendō qui aurait vu le jour à l'époque de Kamakura, dans la région de Mimasaka au nord du département d'okayama. Autrefois tenu dans une douzaine de temples Shingon et Tendai, et sanctuaires de la région, le rite du Gohō n'est plus effectué que dans trois temples; c'est à celui du Ryōsanji que s'intéresse la présente étude.

2 A travers la description des conditions des terrains menés sur deux ans, le premier chapitre vise à retracer la construction du sujet, ainsi que l'évolution de ma méthode à la suite de la fréquentation des cours d'ethnologie (L3 à Nanterre et séminaires à l'EPHE et l'EHESS). Toute la réflexion qui s'ensuit étant largement basée sur ces terrains, j'ai tenu à mettre par écrit leur déroulement afin d'ancrer l'analyse dans un contexte bien défini, prenant en compte la place des acteurs du rite et ma position vis-à-vis d'eux. Ce chapitre témoigne aussi du souci de me démarquer des recherches précédentes qui évoquent le rite sans qu'aucun véritable travail de terrain n'ait été mené.

Le deuxième chapitre est consacré à la description des préparatifs préalables au rite et au déroulement du rite. La description des divers préparatifs est mêlée à une réflexion sur le changement de nature de la population qui participe au rite. Les rôles qui faisaient jusqu'à peu l'objet d'une transmission de père en fils au sein de familles géographiquement proches du temple sont désormais attribués, en cas d'interruption de transmission, à des fidèles du temple qui résident parfois loin et ne prenaient jusqu'alors pas part au rite avant d'avoir été sollicités. On constate ainsi l'élargissement de la communauté impliquée dans le rite ; au critère géographique s'ajoute désormais 
celui de l'affiliation au temple, et ce afin de remédier aux problèmes d'organisation qui se posent avec le vieillissement de la population. L'ascèse de l'homme qui sera possédé lors du rite, le Gohōzane, est ensuite détaillée et maladroitement comparée à un rite de passage quand, me semble-t-il avec le recul, il aurait été plus judicieux de dresser un parallèle avec les ascèses auxquelles se livrent les shugenja. Enfin, le déroulement du rite est relaté séquence par séquence, notamment celles des deux possessions : dans la montagne lorsque la procession conjointe des acteurs et des spectateurs va chercher l'ascète (gogeishin), et dans le temple où a lieu la prière de possession (o-inori) donnant lieu au « jeu » de la divinité (o-asobi). Cette partie fait également mention de la légende selon laquelle une personne attrapée par le Gohōzane lors de sa possession est vouée à mourir dans les trois années qui suivent, ce qui nous permet de discuter de la tonalité de ce rite dans lequel l'implication des spectateurs est particulièrement importante.

4 Le troisième chapitre est consacré à l'analyse du rite. Ayant remarqué que les deux séquences de possession sont construites en opposition, l'hypothèse est émise que la première séquence sert à valoriser le travail collectif (communauté locale, moines et shugenja) mis en œuvre dans la seconde et qui donne lieu à la séquence centrale du rite, celle du « jeu » (la course du Gohōzane à travers la cour du temple parmi la foule des spectateurs). Il est aussi postulé que l'une des raisons de la longévité de ce rite est à chercher dans la forme particulière de ce jeu qui, notamment par le biais de la légende, manifeste une grande capacité à intégrer les spectateurs et à les promouvoir acteurs ce qui, en retour, contribue à maintenir le rite en vie. Enfin, les positions des chercheurs ayant fait mention de ce rite sont examinées. Une place particulière est accordée à la déconstruction de la thèse de Shintani Takanori, selon laquelle ce rite pourrait s'expliquer à la lumière de la notion de souillure. Ma conclusion tend à accréditer la thèse de la plupart des chercheurs, qui affirment qu'il s'agissait certainement à l'origine, d'une sorte de rite de possession du shugendō (yorigitō).

5 Le dernier chapitre traite des enjeux actuels auxquels sont confrontés les acteurs du rite. En reprenant certains aspects auparavant esquissés, le rite est examiné à travers les questions du tourisme et de la patrimonialisation. Ce chapitre rend compte des divers ajustements, formels et structurels, effectués en réaction au vieillissement de la population locale d'une part et à la venue d'un public nouveau et non familiarisé avec le rite d'autre part. Divers aspects laissent ainsi supposer que le rite tend à la spectacularisation, processus qui semble pour l'heure être freiné par l'existence de la légende qui plane sur le rite et qui, si elle constitue une entrave à son inscription au patrimoine culturel immatériel national, contribue en revanche à le maintenir vivant en faisant affluer de nouveaux visiteurs.

6 L'objectif de ce mémoire était ainsi de replacer l'étude de ce rite dans son contexte contemporain afin de dégager les mécanismes qui prévalent à son adaptation dans le temps, plutôt que de le considérer, comme le font les précédentes recherches, uniquement en tant que survivance permettant de retracer « le passé chamanique du shugendō ». Cette approche permet de mettre en évidence une dimension fondamentale négligée dans les travaux antérieurs, celle de la participation de toute une communauté. 